\title{
Relation Between Contractile Response of Akinetic Segments During Dobutamine Stress Echocardiography and Myocardial Ischemia Assessed by Simultaneous Thallium-201 Single-Photon Emission Computed Tomography
}

\author{
Abdou Elhendy, MD, PhD, Jan H. Cornel, MD, Jos R.T.C. Roelandt, MD, PhD, \\ Ron T. van Domburg, MSc, Peter R. Nierop, MD, Marcel L. Geleÿnse, MD, \\ Galal M. El-Said, MD, and Paolo M. Fioretti, MD, PhD
}

There are no standard criteria for the diagnosis of myocardial ischemia in akinetic segments during dobutamine stress echocardiography (DSE). The aim of the study was to assess the relation between different responses of akinetic segments during DSE and ischemia assessed by thallium-201 single-photon emission computed tomography (SPECT). Dobutamine-atropine stress echocardiography with simultaneous stress-reinjection thallium-201 SPECT was performed in 67 patients with old myocardial infarction significant and coronary artery stenosis. Fourteen myocardial segments were matched for both DSE and SPECT. Ischemia on SPECT was defined as reversible thallium defects. In 257 akinetic segments, 4 patterns during DSE were identified: (1) biphasic response in 41 segments $(16 \%)$, defined as improvement at low dose (5 to $10 \mu \mathrm{g} / \mathrm{kg} / \mathrm{min})$ followed by worsening at high dose; (2) persistent akinesia in 155 segments $(60 \%)$; (3) akinesia becoming dyskinesia in 39 segments (15\%); and (4) sustained improvement in 22 segments

D obutamine stress testing in conjunction with echocardiography or myocardial perfusion scintigraphy is increasingly being used for the diagnosis and functional evaluation of coronary artery disease. ${ }^{1-9}$ The standard echocardiographic criteria for the diagnosis of ischemia rely upon the occurrence of new or worsening wall motion abnormalities. ${ }^{1-4}$ However, in severely dyssynergic segments no further deterioration of function can occur during the test, and consequently the diagnosis of ischemia in these segments represents a limitation of the echocardiographic technique. It was suggested that a "biphasic response" manifested as a contractile response at low-dose dobutamine followed by worsening at a high dose is a sign of myocardial

From the Thoraxcenter and the Deparment of Nuclear Medicine University Hospital Rotterdam-Dijkzigt and Erasmus University, Rotterdam, The Netherlands. This study was supported in part by the Department of Cardiology, Cairo University Hospital, Cairo, Egypt. Manuscript received September 5, 1995; revised manuscript received and accepted November 27, 1995

Address for reprints: Paolo M. Fioretti, MD, PhD, Thoraxcenter, Ba 300, Dr Molewaterplein 40,3015 GD Rotterdam, The Nether lands.
$(9 \%)$. Reversible thallium defects were defected in 21 segments $(51 \%)$ in group 1 , in 20 segments $(13 \%)$ in group 2, none in group 3, and in 2 segments in group $4(9 \%)$. The prevalence of reversible defects in biphasic segments was higher compared with other patterns ( $p$ $<0.00001$ vs groups 2 and $3, p<0.005$ vs group 4). The ischemic perfusion defect score was significantly higher in group 1 than group 2. The positive predictive value of biphasic response for reversible thallium defects was similar to that of stress-induced dyssynergia in normal segments at rest (51\% vs $58 \%$ ). It is concluded that of the various responses of akinetic segments to dobutamine infusion, the biphasic response is associated with the highest prevalence and greatest severity of ischemia on thallium SPECT. Observation of contractile response at both low- and high-dose DSE is a valuable approach for the diagnosis of myocardial ischemia in akinetic segments.

(Am J Cardiol 1996;77:955-959)

ischemia. ${ }^{10,11}$ However, little data are available to confirm this conclusion. The diagnosis of myocardial ischemia by dobutamine perfusion scintigraphy is based on the occurrence of reversible perfusion defects. $^{4-6}$ Because the technique is not dependent on interpretation of wall motion, it can be used for evaluation of ischemia in akinetic segments. Therefore, the aim of this study was to assess the relation between different responses of akinetic segments during dobutamine stress echocardiography (DSE) and ischemia on simultaneous thallium-201 single-photon emission computed tomography (SPECT) myocardial perfusion imaging in patients with previous myocardial infarction.

\section{METHODS}

Patient selection: The study population was composed of 67 consecutive patients with previous myocardial infarction $>3$ months old and exertional chest pain who had been referred to our imaging laboratory for evaluation of myocardial ischemia. Dobutamine-atropine stress echocardiography was performed in these patients in conjunction with thallium-201 SPECT imaging, and the images were 
technically interpretable. The diagnosis of myocardial infarction relied on the standard criteria of prolonged chest pain, a diagnostic rise of serum creatine kinase, and serial electrocardiographic changes. $\mathrm{Pa}-$ tients were included if they had $\geq 2$ akinetic segments on their baseline echocardiogram. Mean age was $59 \pm 9$ years. There were 55 men and 12 women. Forty-seven patients $(70 \%)$ were receiving oral nitrates and/or calcium antagonists on the day of the test. Prescribed $\beta$ blockers were stopped 2 days before the test.

Dobutamine stress test: Dobutamine was infused through an antecubital vein in 3-minute stages, starting at a dose of $5 \mu \mathrm{g} / \mathrm{kg} / \mathrm{min}$, increasing to $10 \mu \mathrm{g} /$ $\mathrm{kg} / \mathrm{min}$, and then increasing by $10 \mu \mathrm{g} / \mathrm{kg} / \mathrm{min}$ to a maximum of $40 \mu \mathrm{g} / \mathrm{kg} / \mathrm{min}$. Atropine ( $\leq 1 \mathrm{mg}$ ) was given to patients who did not achieve $85 \%$ of their age-predicted maximal heart rate at peak dobutamine dose. ${ }^{12}$ The electrocardiogram was monitored during infusion and recorded each minute. Cuff blood pressure was measured every 3 minutes. The test was interrupted if severe chest pain, ST-segment depression $>2 \mathrm{~mm}$, significant ventricular or supraventricular arrhythmia, or systolic blood pressure fall $>40$ $\mathrm{mm} \mathrm{Hg}$ occurred.

Stress echocardiography: Echocardiographic images were acquired at rest, during the test, and during recovery. For both rest and stress studies, the left ventricular wall was divided into 16 segments and scored with a 4-point scale where $1=$ normal, $2=$ hypokinesis, $3=$ akinesia, and $4=$ dyskinesia. $^{1,3}$ Both wall motion and thickening were considered for analysis. Each segment was scored at rest, at lowdose dobutamine, and at peak stress. Criteria for diagnosis of ischemia were the appearance of wall motion abnormalities during stress in $\geq 1$ normal segment at rest and the occurrence of akinesia or dyskinesia during stress in $\geq 1$ hypokinetic segment at rest. Images were recorded on videotape and digitized on optical disk (CFM 800 Vingmed, Norway) and displayed side by side in quad-screen format to facilitate comparison of rest, low-dose, and peak stress images. Image interpretation was performed by 2 experienced observers without knowledge of the patients' scintigraphic data. In case of disagreement, a majority decision was made by a third reviewer. In our laboratory inter- and intraobserver agreement for echocardiographic assessment were $84 \%$ and $87 \%$ for resting images and $92 \%$ and $94 \%$ for dobutamine stress images, respectively. ${ }^{13}$ Four patterns of contractile response in akinetic segments during DSE were identified: (1) biphasic response, defined as akinetic segments demonstrating a contractile response at low-dose dobutamine ( 5 to 10 $\mu \mathrm{g} / \mathrm{kg} / \mathrm{min}$ ) and becoming akinetic at peak stress; (2) persistent akinesia, defined as unchanged akinetic pattern throughout the test; (3) akinesia at rest becoming dyskinesia at peak stress; and (4) sustained improvement, defined as akinetic segment at rest becoming normal or hypokinetic at low dose, without worsening at peak stress.
Thallium single-photon emission computed tomography imaging: Approximately 1 minute before termination of the stress test, an intravenous dose of 74 MBq of thallium-201 was administered. ${ }^{13}$ The acquisition of stress SPECT imaging was started immediately after the test. For the reinjection studies, imaging was acquired 4 hours after the stress test, 20 minutes after reinjection of $37 \mathrm{MBq}$ thallium. For each study 6 oblique (short-axis) slices from the apex to the base and 3 sagittal (vertical long-axis) slices from the septum to the lateral wall were defined. Each of the 6 short-axis slices was divided into 8 equal segments. The septal part of the 2 basal slices (4 segments) was not considered for analysis because this region corresponds to the fibrous portion of the interventricular septum and normally exhibits reduced uptake. Interpretation of the scan was performed by visual analysis assisted by the circumferential profiles analysis. Stress and reinjection tomographic views were reviewed in side-by-side pair by an experienced observer who was unaware of the patients' echocardiographic data. A reversible perfusion defect was defined as a perfusion defect on stress images that partially or completely resolved at reinjection imaging in 2 or more contiguous segments or slices. This was considered diagnostic of ischemia. A fixed perfusion defect was defined as a perfusion defect on stress images in 2 or more contiguous segments or slices that persisted on reinjection images. The perfusion defect score was quantitatively calculated by measuring the area between the lower limit of normal values ( \pm 2 SDs) and the actual circumferential profile in 6 short-axis slices. The ischemic perfusion score was derived by subtracting the rest from the stress score. Myocardial segments identified during scintigraphy were matched with those identified during echocardiography in a 16-segment model. The basal septal segments were excluded from analysis.

Coronary angiography: Coronary angiography was performed with the Judkins technique in $\leq 3$ months in all patients. Significant coronary artery disease was defined as a stenosis diameter $\geq 50 \%$ in $\geq 1$ major epicardial artery, using a quantitative method described previously. ${ }^{14}$ Coronary arteries were assigned to particular myocardial segments as previously described. ${ }^{3,15}$

Statistical analysis: Unless specified, data are presented as mean values $\pm \mathrm{SD}$. The chi-square test and Fisher's exact test were used to compare differences between proportions. The Student $t$ test was used for analysis of continuous data. A p $<0.05$ was considered statistically significant.

\section{RESULTS}

Dobutamine stress test: Heart rate increased from $73 \pm 13$ at rest to $137 \pm 15$ beats $/ \mathrm{min}$ at peak stress $(\mathrm{p}<0.0001)$, whereas systolic blood pressure did not change $(125 \pm 21$ at rest vs $123 \pm 25 \mathrm{~mm} \mathrm{Hg}$ at peak stress). There was no significant increase in heart rate or systolic blood pressure at low-dose dobutamine compared with baseline values $(82 \pm 17$ 
TABLE I Scintigraphic Pattern, Quantitative Perfusion Defect Score, and Prevalence of Significant Stenosis of the Related Coronary Artery in Akinetic Segments Identified According to Response to Dobutamine Infusion

\begin{tabular}{|c|c|c|c|c|}
\hline & $\begin{array}{c}\text { Group 1-Biphasic } \\
\qquad(\mathrm{n}=41)\end{array}$ & $\begin{array}{c}\text { Group } 2 \text {-Persistent } \\
\text { Akinesia } \\
(\mathrm{n}=155)\end{array}$ & $\begin{array}{c}\text { Group 3-Akinesia } \\
\text { to Dyskinesia } \\
(n=39)\end{array}$ & $\begin{array}{c}\text { Group } 4 \text {-Sustained } \\
\text { Improvement } \\
(n=22)\end{array}$ \\
\hline Reversible effect & $21(51 \%)$ & $20(13 \%)$ & 0 & $2(9 \%)$ \\
\hline Complete & $5(12 \%)$ & $6(4 \%)$ & 0 & $2(9 \%)$ \\
\hline Partial & $16(39 \%)$ & $14(9 \%)$ & 0 & 0 \\
\hline Fixed defect & $16(39 \%)$ & $127(82 \%)$ & $39(100 \%)$ & $11(50 \%)$ \\
\hline Normal & $4(10 \%)$ & $8(5 \%)$ & 0 & $9(41 \%)$ \\
\hline Stress defect score & $279 \pm 220$ & $294 \pm 265$ & $307 \pm 180$ & $100 \pm 130$ \\
\hline Reinjection defect score & $140 \pm 170^{*}$ & $273 \pm 255$ & $302 \pm 177$ & $90 \pm 110^{*}$ \\
\hline Ischemic defect score & $136 \pm 142^{\dagger}$ & $56 \pm 90$ & 0 & $80 \pm 16$ \\
\hline Coronary stenosis $\geq 50 \%$ & $37(90 \%)$ & $132(85 \%)$ & $35(90 \%)$ & $15(68 \%)^{\ddagger}$ \\
\hline
\end{tabular}

beats/min and $124 \pm 23 \mathrm{~mm} \mathrm{Hg}$, respectively). Angina occurred in 37 patients $(55 \%)$, ST-segment depression in 22 patients (33\%), and ST-segment elevation in 28 patients $(42 \%)$. The test was interrupted before the maximal dose or the target heart rate was reached because of angina in 4 patients, STsegment depression in 1 , hypotension in 7 , and significant tachyarrhythmias in 1 .

Stress echocardiography: A total of 257 akinetic segments were identified on the baseline echocardiogram. Four groups of akinetic segments were identified: (1) biphasic response detected in 17 patients $(25 \%)$, in 41 segments (16\%); (2) persistent akinesia in 50 patients $(75 \%)$, in 155 segments $(60 \%)$; (3) akinesia becoming dyskinesia in 14 patients (21\%), in 39 segments (15\%); none of these segments improved at low dose; (4) sustained improvement, detected in 10 patients $(15 \%)$, in 22 segments (9\%). Some patients had different responses in different segments. In the 63 segments with contractile response at low-dose dobutamine, the response was observed at a dose of $5 \mu \mathrm{g} / \mathrm{kg} / \mathrm{min}$ in 18 segments and at $10 \mu \mathrm{g} / \mathrm{kg} / \mathrm{min}$ in 45 segments. There was no significant difference between the 4 groups in the corresponding heart rate or systolic blood pressure at rest, low dose, and peak stress. New wall motion abnormalities were detected in 89 of 403 segments $(22 \%)$ with normal baseline contraction.

Thallium-201-single-photon emission computed tomography imaging: The distribution of scintigraphic patterns is presented in Table 1. Group 1 was composed of segments with the highest prevalence of reversible perfusion defects ( $p<0.00001$ vs groups 2 and $3, p<0.005$ vs group 4 ). The prevalence of reversible thallium defects was higher in group 2 versus group $3(p<0.05)$, while the difference was not significant in group 2 versus 4 and in group 3 versus 4 (Figure 1). The perfusion defect score at reinjection was lower in group 4 than other groups $(\mathrm{p}<0.05)$ and lower in group 1 versus 2 and $3(p$ $<0.05$ ). Normal perfusion was detected in $21 \mathrm{seg}$ ments (8\%) and did not tend to involve a particular anatomic location. The ischemic perfusion score was higher in group 1 than $2(p<0.05)$ (Table I). In
FIGURE 1. Prevalence of reversible perfusion defects in akinetic segments with biphasic response, persistent akinesia, akinesia becoming dyskinesia, and akinesia with sustained improvement.

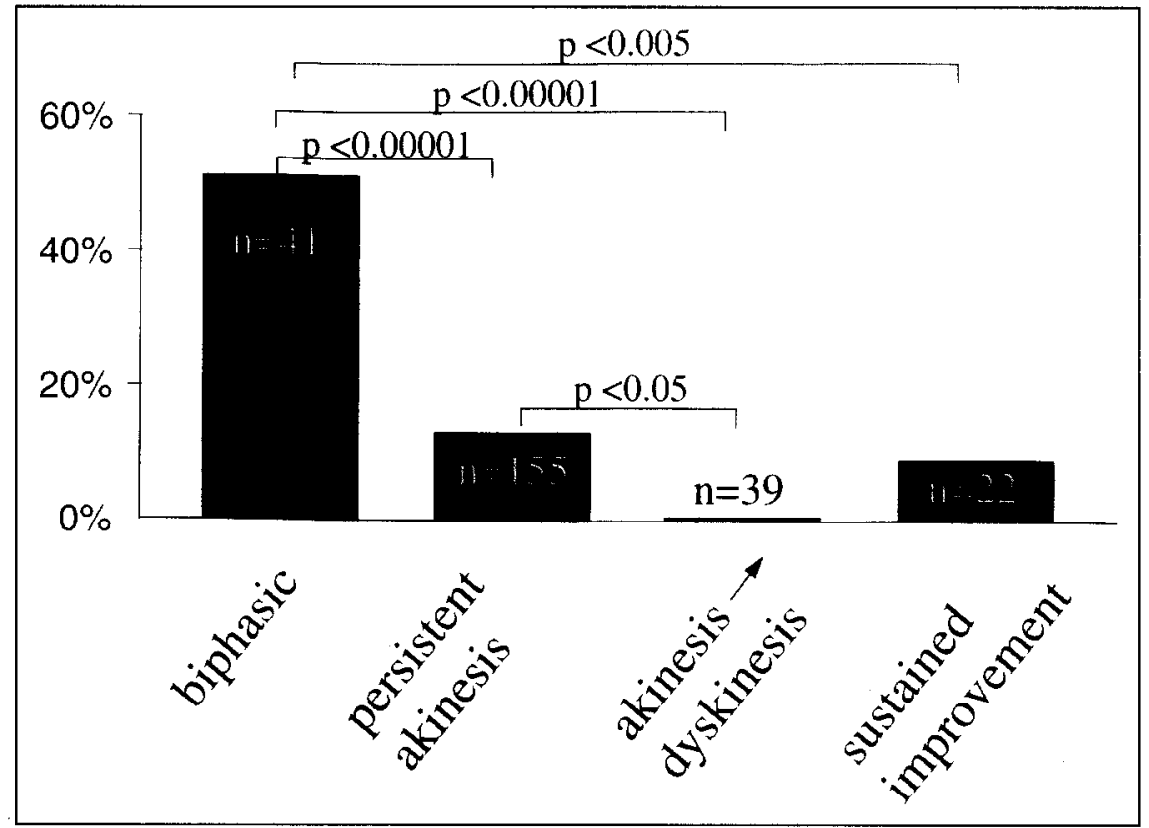


myocardial segments with normal contraction at rest, reversible perfusion defects were detected in 52 of 89 segments ( $58 \%$ ) with stress-induced wall motion abnormalities and in 18 of 314 segments $(6 \%)$ without stress-induced wall motion abnormalities ( $p$ $<0.00001$ ). The prevalence of reversible perfusion defects in akinetic biphasic segments was not different compared with segments with normal baseline contraction and stress-induced wall motion abnormalities (51\% vs $58 \%$ ).

Coronary angiography: Significant coronary artery disease was detected in all patients. Twelve patients (18\%) had 1-vessel disease, 25 (37\%) had 2-vessel disease, and $30(45 \%)$ had 3-vessel disease. There was no significant difference between groups 1, 2, or 3 with respect to prevalence of stenosis in the related artery, whereas the prevalence was higher in each of these groups compared with group 4 ( $p$ $<0.05$ in all) (Table I) .

\section{DISCUSSION}

Our results show that among the 4 different contractile responses of akinetic segments during DSE, a biphasic response was associated with the highest prevalence of reversible perfusion defects (and presumably ischemia) compared with segments with persistent akinesia, sustained improvement, and akinesis becoming dyskinesia. The degree of reversibility as measured by ischemic perfusion score was greater in segments with biphasic response compared with those with persistent akinesia by quantitative analysis. Furthermore, the use of a biphasic response in akinetic segments as a criterion for ischemia gave a positive predictive value comparable to the standard criterion of a normal segment becoming dyssynergic during stress. The relation between a biphasic response and ischemia can be explained by the presence of a hibernating viable myocardium subtended by a stenotic coronary artery, which exhibits a contractile response to low-dose dobutamine and ischemia provoked by an increase of heart rate and flow maldistribution at high-dose dobutamine. ${ }^{16}$ Nevertheless, $51 \%$ of reversible perfusion defects in akinetic segments were not in the biphasic group. Reversible thallium defects occurred infrequently in akinetic segments with sustained improvement (9\%) and in persistently akinetic segments $(13 \%)$. Segments with persistent akinesia and reversible thallium-201 defects may represent a hibernating myocardium unresponsive to dobutamine or severely necrotic myocardium with a small amount of viable, ischemic myocardium resulting in reversible hypoperfusion yet incapable of demonstrating a contractile response at low-dose dobutamine. Panza et al ${ }^{17}$ concluded that the cellular mechanism responsible for thallium uptake requires a lesser degree of myocyte functional integrity than does the mechanism responsible for positive inotropic response to dobutamine, which may explain the presence of reversible perfusion defects in some segments with persistent akinesia. These investigators demonstrated that the positive inotropic response of dyssynergic myocar- dium to low-dose dobutamine is directly related to thallium uptake, ${ }^{17}$ which is compatible with our findings of more severe fixed perfusion defects and fewer severe reversible perfusion defects in persistently akinetic segments compared with biphasic segments. The absence of reversible perfusion defects in akinetic segments becoming dyskinetic at highdose dobutamine supports our previous report, in which this pattern was attributed to passive myocardial bulging unrelated to myocardial ischemia. ${ }^{18}$ The presence of normal perfusion in $8 \%$ of akinetic segments in our study is difficult to explain. Myocardial stunning is a possible mechanism, which may be supported by the finding of the highest prevalence of normal perfusion and lowest prevalence of significant coronary stenosis in segments with persistent improvement. However, it is not known if myocardial stunning can exist $>3$ months after infarction. Other explanations may include methodologic limitations in detecting reversible defects and difficulties in registration of images obtained with different methodologies.

Comparison with previous studies: Senior and Lahiri ${ }^{10}$ reported that the use of biphasic response increased the sensitivity of DSE for the detection of reversible defects on simultaneous MIBI or tetrofosmin SPECT in 44 patients with left ventricular dysfunction. However, the contribution of other responses of akinetic segments was not studied. Furthermore, a global rather than a matched segmental analysis was used. Biphasic response to dobutamine infusion in animal studies was shown to be characteristic of ischemic or short-term hibernation. Worsening of wall motion at a high dose was associated with myocardial acidosis and lactate accumulation. ${ }^{19}$

Lack of improvement of contractility during DSE was described as a sign of ischemia due to exhaustion of coronary reserve. ${ }^{5,6,20}$ However, this is more likely to be applicable to normal or hypokinetic rather than akinetic segments.

Study limitations: Myocardial ischemia was assessed by thallium perfusion scintigraphy, which detects flow malperfusion as well as true ischemia. Despite the fact that reinjection enhances the detection of reversible perfusion defects, ${ }^{21}$ some of these defects can be missed if redistribution images were not acquired. ${ }^{22}$ However, it is unlikely that underestimation of defect reversibility will occur more frequently in a particular group of segments. Although biphasic akinetic segments showed the highest prevalence of reversible thallium defects, the positive predictive value of this pattern for reversible perfusion defects was not high. However, the predictive value was comparable to that of the standard criterion of a normal segment becoming dyssynergic during stress. This may be explained by the previously mentioned limitations of correlating 2 imaging modalities that detect different pathophysiologic sequela of coronary artery disease.

Conclusion: In symptomatic patients with left ventricular dysfunction after myocardial infarction, a bi- 
phasic response of akinetic segments during DSE is associated with the highest prevalence and most severe myocardial ischemia on the basis of thallium201 SPECT compared with segments with persistent akinesia, sustained improvement, and akinetic segments becoming dyskinetic. The positive predictive value of a biphasic response for reversible thallium defects is comparable to that obtained by the standard echocardiographic criteria for ischemia in segments with normal baseline contraction. Observation of contractile response of akinetic segments at both low- and high-dose DSE may provide a valuable approach for the echocardiographic diagnosis of myocardial ischemia in akinetic segments.

1. Sawada SG, Segar DS, Ryan T, Brown SE, Dohan AM, Williams R, Fineberg NS, Armstrong WF, Feigenbaum H. Echocardiographic detection of coronary artery disease during dobutamine infusion. Circulation 1991;83:1605-1614. 2. Salustri A, Fioretti PM, Pozzoli MMA, McNeill AJ, Roelandt JRTC. Dobutamine stress echocardiography: its role in the diagnosis of coronary artery disease. Eur Heart J 1992:13:70-77.

3. Segar DS, Brown SE, Sáwada SG, Ryan T, Feigenbaum H. Dobutamine stress echocardiography: correlation with coronary lesion severity as determined by quantitative angiography. J Am Coll Cardiol 1992;19:1197-1202.

4. Forster T, McNeill AJ, Salustri A, Reijs AEM, El-Said EM, Roelandt JRTC, Fioretti PM. Simultaneous dobutamine stress echocardiography and 99-m technetium isonitrile single photon emission computed tomography in patients with suspected coronary artery disease. J Am Coll Cardiol 1993;21:1591 1596.

5. Marwick T, Willemart B, D'hondt AM, Baudhuin T, Wijns W, Detry JM, Melin J. Selection of the optimal nonexercise stress for the evaluation of ischemic regional myocardial dysfunction and malperfusion: comparison of dobutamine and adenosine using echocardiography and $99 \mathrm{~m}$ Tc-MIBI single photon emission computed tomography. Circulation 1993:87:345-354

6. Mairesse GH, Marwick TH, Vanoverschelde JL, Baudhuin T, Wijns W, Melin JA, Detry JM. How accurate is dobutamine stress electrocardiography for detection of coronary artery disease? Comparison with two-dimensional echocardiography and technetium $-99 \mathrm{~m}$ methoxyl isobutyle isonitrile (Mibi) perfusion scintigraphy. J Am Coll Cardiol 1994;24:920-927.

7. Berthe C, Pierard LA, Hiernaux M, Trotteur G, Lempereur P, Carlier J, Kulbertus HE. Predicting the extent and location of coronary artery disease in acute inyocardial infarction by echocardiography during dobutamine infusion. Am J Cardiol 1986;58:1167-1172.

8. Pierard LA, De Landsheere CM, Berth C, Rigo P, Kulbertus HE. Identification of viable myocardium by echocardiography during dobutamine infusion in patients with myocardial infarction after thrombolytic therapy: comparison with positron emission tomography. J Am Coll Cardiol 1990;15:1021-1031.
9. Hays JT, Mahmarian JJ, Cochran AJ, Verani MS. Dobutamine thallium-201 tomography for evaluating patients with suspected coronary artery disease unable to undergo exercise or vasodilator pharmacologic stress testing. $J \mathrm{Am} \mathrm{Coll}$ Cardiol 1993;21:1583-1590.

10. Senior R, Lahiri A. Enhanced detection of myocardial ischemia by stress dobutamine echocardiography utilizing the "biphasic" response of wall thickening during low and high dose dobutamine infusion. J Am Coll Cardiol 1995;26:26-32.

11. Pierard LA. Comparison of approaches in the assessment of myocardial viability and follow up of PTCA/CABG: the role of echocardiography. Int $J$ Card Imag 1993;9:11-17.

12. McNeill AJ, Fioretti PM, El-Said EM, Salustri A, Forster T, Roelandt JRTC. Enhanced sensitivity for detection of coronary artery disease by addition of atropine to dobutamine stress echocardiography. Am J Cardiol 1992;70:41-46. 13. Arnese M, Cornel JH, Salustri A, Maat APWM. Elhendy A. Reijs AEM, Ten Cate FJ, Keane D, Balk AHMM, Roelandt JRTC, Fioretti PM. Prediction of improvement of regional left ventricular function after surgical revascularization: a comparison of low-dose-dobutamine echocardiography with 201-T] single-photon emission computed tomography. Circulation 1995;91:2748 2752

14. Baptista J, Arnese M, Roelandt JRTC, Fioretti P, Keane D, Escaned J, Boersma E, Di Marjo C. Serruys PW. Quantitative coronary angiography in the estimation of the functional significance of coronary stenosis: correlation with dobutamine-atropine stress test. J Am Coll Cardiol 1994;23:1434-1439.

15. Bourdillon PDV, Broderik TM, Sawada SG, Armstrong WF, Ryan T, Dillon JC, Fineberg NS. Feigenbaum H. Regional wall motion index for infarct and non-infarct region after reperfusion in acute myocardial infarction: comparison with global wall motion index. $J$ Am Soc Echocardiogr 1989:2:398-407.

16. Ruffolo RR. The pharmacology of dobutamine. Am J Med Sri 1987:294:244-248

17. Panza JA, Dilsizian V, Laurienzo JM, Curiel RV, Katsiyiannis PT. Relation between thallium uptake and contractile response to dobutamine: implication regarding myocardial viability in patients with chronic coronary artery disease and left ventricular dysfunction. Circulation 1995;91:990-998.

18. Arnese M, Fioretti PM, Cornel JH. Postma-Tjoa J, Reijs AEM, Roeland JRTC. Akinesis becoming dyskinesis during high-dose dobutamine stress echocardiography: a marker of myocardial ischemia or a mechanical phenomenon? Am J Cardiol 1994;73:896-898.

19. Chen C, Li L, Long Chen L, Prada JV, Hui Chen M, Fallon JT, Weyman AE, Waters D. Gillam L. Incremental doses of dobutamine induce a biphasic response in dysfunctional left ventricular regions subtending coronary stenoses. Circulation 1995:92:756-766

20. Perrone-Fillardi P, Pace L, Prastaro M, Piscione F, Betocchi S, Squame F, Vezzuto P, Soricelli A, Indolfi C, Salvatore M. Dobutamine echocardiography predicts improvement of hypoperfused dysfunctional myocardium after revascularization in patients with coronary artery disease. Circulation 1995;91:25562565.

21. Dilsizian V. Rocco TP. Freedman NM, Leon MB, Bonow RO. Enhanced detection of ischemic but viable myocardium by the reinjection of thatlium after stress-redistribution imaging. $N$ Engl J Med 1990;323:141-146.

22. Dilsizian V, Bonow RO. Differential uptake and apparent $201 \mathrm{Tl}$ washout after thallium reinjection: options regarding late redistribution imaging before reinjection or late redistribution imaging after reinjection. Circulation 1992;85:1032-1038. 